\title{
A scientometric analysis of affordance research in the field of interaction design based on CiteSpace
}

\author{
Qianwen Huang ${ }^{1}$, Yuxiang Kuang ${ }^{1 *}$ and Zemei $\mathrm{Li}^{1}$ \\ ${ }^{1}$ Art College, Jiangxi University of Finance and Economics, Nanchang, Jiangxi Province, 330013, China
}

\begin{abstract}
A method of scientometrics analysis was adopted in this study to objectively visualize the research status quo, track the emerging trends and understand the intellectual structure of affordance research in the field of interaction design with 726 documents published in the ISI Web of Science Core Collection (WoSCC) database from 1995-2020. The results identified that annual trends of the papers will continue to grow. USA plays a significant role and is a pioneer in the field. There is no leading institution or author with high output or high influence. The study has formed 4 hot research topic: Theoretical study, Perception-level study, Behaviour-level study and Experience-level study. According to the references cocitation network, we can know that affordance research in the field of interaction design has produced a number of classic literature.
\end{abstract}

\section{Introduction}

The concept of Affordances was firstly given in 1977 by James Gibson, an American ecological psychologist, to mean what the environment "offers the animal, what it provides or furnishes, either for good or ill"'[1]. Then, the notion was introduced to design in 1988 by Donald Norman defining affordances as "the perceived or actual properties of the thing, primarily those fundamental properties that determine just how the thing could possibly be used"[2]. That a great number of researchers, designers and educators utilized affordances about the direct perception of possibilities for action to make things more intuitive and usable, turned it quickly into a fundamental and basic principle in interaction design and HCI $[3$, 4]. Affordances have received significant attention from the field of interaction design and HCI.

Previous researchers have reviewed affordances in the field of interaction design and HCI. Victor Kaptelinin overviewed affordances in HCI from four main themes including "affordances in Ecological Interface Design, specifying affordance as an HCI concept, reframing affordances from non-Gibsonian theoretical perspectives, and exploring alternative or complementary concepts"[5]. Chaomin Ma introduced the research status quo and the applications of affordances in the field of interaction design[6]. However, traditional literature reviews are mostly based on qualitative conclusion of selected literature, which tends to be subjective while systematic review is more concise and comprehensive[7].

In terms of the increasingly significant theoretical value of affordances in the field of interaction design, this paper intends to make a systematic and comprehensive review of affordance research in the field of interaction design, which will be beneficial for beginners immediately to master research status quo, hot research topics, research fronts and intellectual structure.

\section{Data and Methods}

\subsection{Data collection}

For ensuring the credibility, reliability and high-quality of raw data, the data for this research were collected from six Citation Indexes in the ISI Web of Science Core Collection (WoSCC) database, including the Science Citation Index Expanded (SCI-EXPANDED), Social Sciences Citation Index (SSCI), Arts \& Humanities Citation Index (A\&HCI), Conference Proceedings Citation Index-Science (CPCI-S), Conference Proceedings Citation Index-Social Science \& Humanities (CPCI-SSH) and Emerging Sources Citation Index (ESCI). The following retrieval content was used in Advanced Search: "TS = (affordance* AND interaction design) OR TS $=$ (affordance* AND human computer interaction)". The time span was from 1988 to 2020 (as of 20 April 2020). A total of 742 records were extracted with the first paper appearing in 1995. After refining the document types to article and proceeding paper with higher-quality information, 726 records left were selected for following analysis.

\subsection{Methods}

*Corresponding author’s e-mail: kyxiang@jxufe.edu.cn 
A scientometric analysis (including co-author, co-word, co-citation and cluster analysis) provides a feasible and statistical way to visualize the research status quo, such as influential countries/regions, institutions and authors, track the emerging trends and understand the intellectual structure of a research field[8]. In this paper, CiteSpace $\mathrm{V}$, a Java-based application, is used to analyze the bibliographic records, delineate the co-citation networks and detect the emerging trends.

\section{Distribution characteristics of the Publications}

\subsection{Characteristics of publications}

As shown in figure 1, the distribution of annual publications represents an increasing trend during the time span. The annual average publication from 1995 to 2003 was only about 3 articles, in the infancy phase of the research field. There was a steady increase of the publications from 2004 to 2014, accounting for nearly 38\% of the total records and annual average publication was about 25 articles. That indicated affordance research in the field of interaction design was entering the vision of academic field. Since 2015, we can find a rapid growth of research interest and 420 articles in total were issued, accounting for $57.9 \%$ of all. In addition, two peak points were observed respectively in 2011 and 2016. Present trend indicated that the number of publications about this study will continue to grow rapidly. 18 articles were searched in 2020 so far, with confidence that we can look forward to have another peak point after this year.

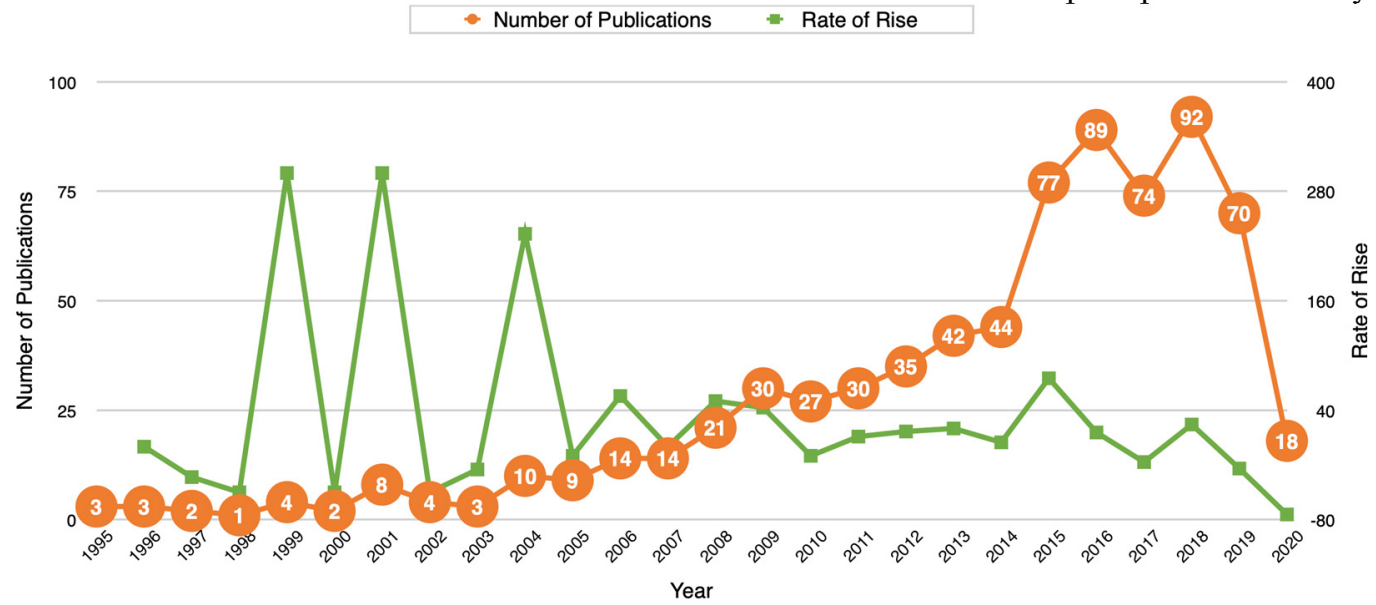

Figure 1. Annual publication characteristics of affordances research in the interaction design on the ISI WoSCC database, 1995-2020(total 726).

publications and high betweenness centrality (0.65)

\subsection{Countries/regions cooperation network analysis}

As shown in figure 2, this network contains 35 nodes and 100 links. According to the network analysis, the leading countries/regions on affordance research in the field of interaction design can be identified. The United States (244 articles), United Kingdom (88 articles), Australia (41 articles), Netherlands (39 articles), France (32 articles) and Canada ( 32 articles) which are at the top of the list proved that these countries/regions made significant contribution to the development of affordance research in the field of interaction design. Here, betweenness centrality is introduced as a key parameter to characterize the influence of country in this research field. According to betweenness centrality, the United States is the pioneer in the field with the highest during the time span obviously.

In terms of betweenness centrality, a country with high centrality has great influence in the network[9]. Countries/regions such as United States (centrality = 0.65 ), United Kingdom (centrality $=0.36$ ), Spain (centrality $=0.16)$, Denmark (centrality $=0.15)$, Netherlands (centrality $=0.12$ ) and France (centrality = 0.12 ), Australia (centrality $=0.11$ ) were the key infrastructure nodes in the network. It is noteworthy that the centrality of USA, the origination of a heavily cited definition of the affordance of Gibson, is significantly higher than other countries. The USA played a significant role in international communication and cooperation related to affordances in the interaction design. Even though Canada (32 articles, centrality $=0$ ) and China $(28$ articles, centrality $=0)$ has high publications, they should strengthen cooperation with other countries for low centrality. 


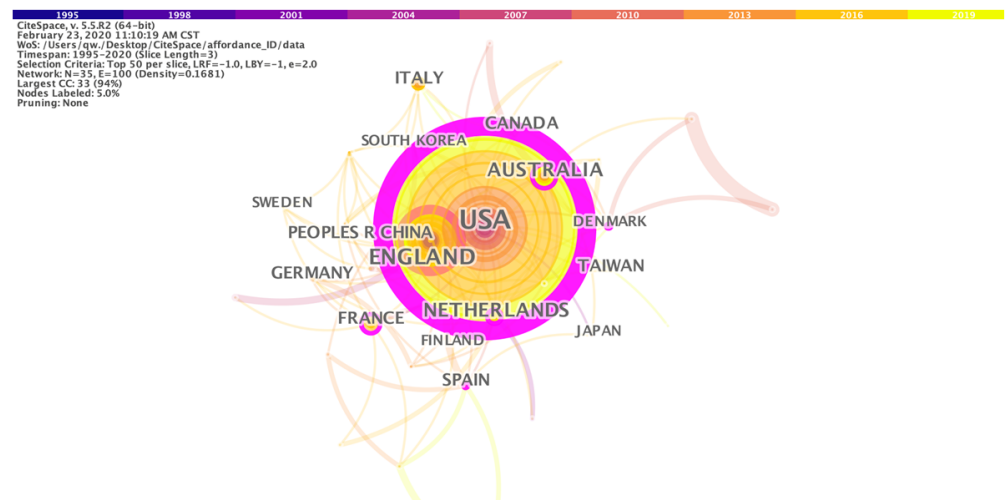

Figure 2. Countries/regions cooperation network.

articles), University Calif Berkeley (7 articles),

\subsection{Institutions cooperation network analysis}

As shown in figure 3 , this network contains 110 nodes and 34 links. The size of the node reflects the publications of the institution. The link between the nodes represents the cooperative relationship. The closer the cooperation is, the thicker the connection is. Penn State University (11 articles), Stanford University (8 University Washington (7 articles), University Illinois (7 articles), Sungkyunkwan University (7 articles) top the list. With few links and low betweenness centrality (all are 0) existing in the network, It's easy to find out that the institutions lack of cooperation with each other and no leading institutions have yet been formed.

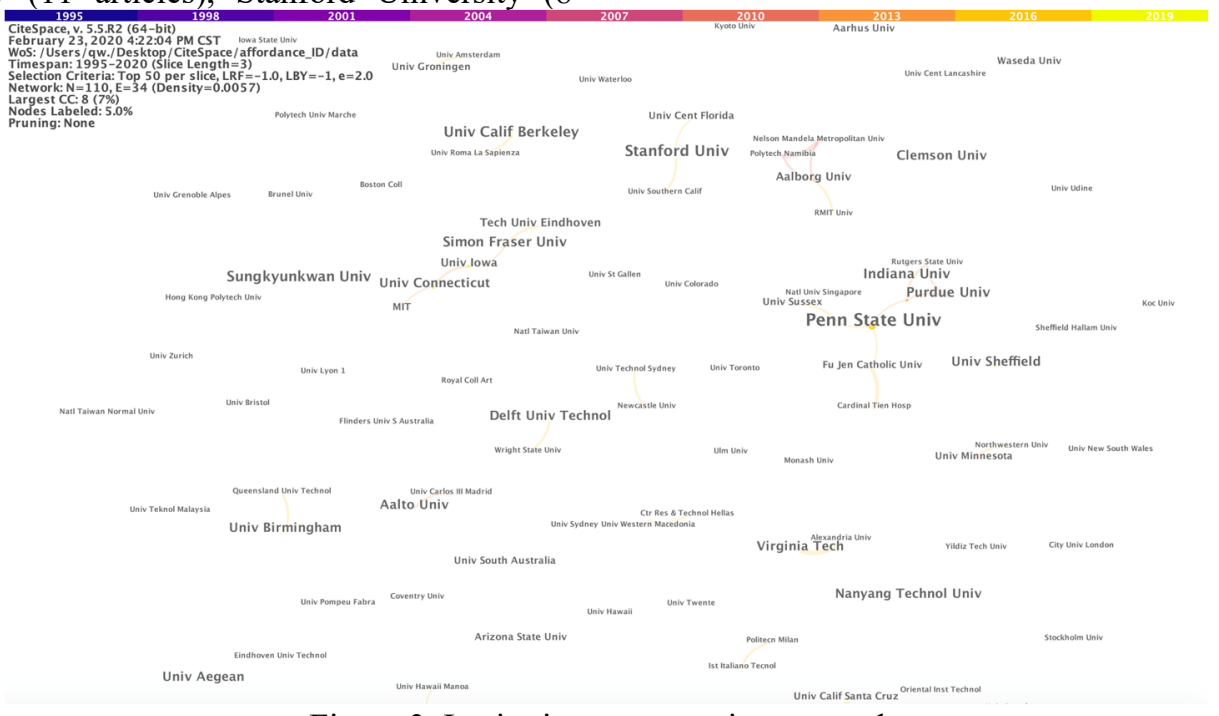

Figure 3. Institutions cooperation network.

\subsection{Authors cooperation network analysis}

As shown in figure 4, this network contains 71 nodes and 43 links. According to the formula proposed by Price (N $=0.749 \sqrt{\text { Npmax }}$, Npmax represents the maximum count of author's publications), there are 71 core authors whose minimum publications should equal 2 or more.
However, there are few high-productive authors and betweenness centrality are all 0 . The authors with the largest number of articles (5 articles) are ELENA MARQUEZ SEGURA, KAATHERINE ISBISTER, YONG SE KIM. At present, the research force and the cooperative relationship in this field are relatively scattered, without a systematic and high-impact leading author. 


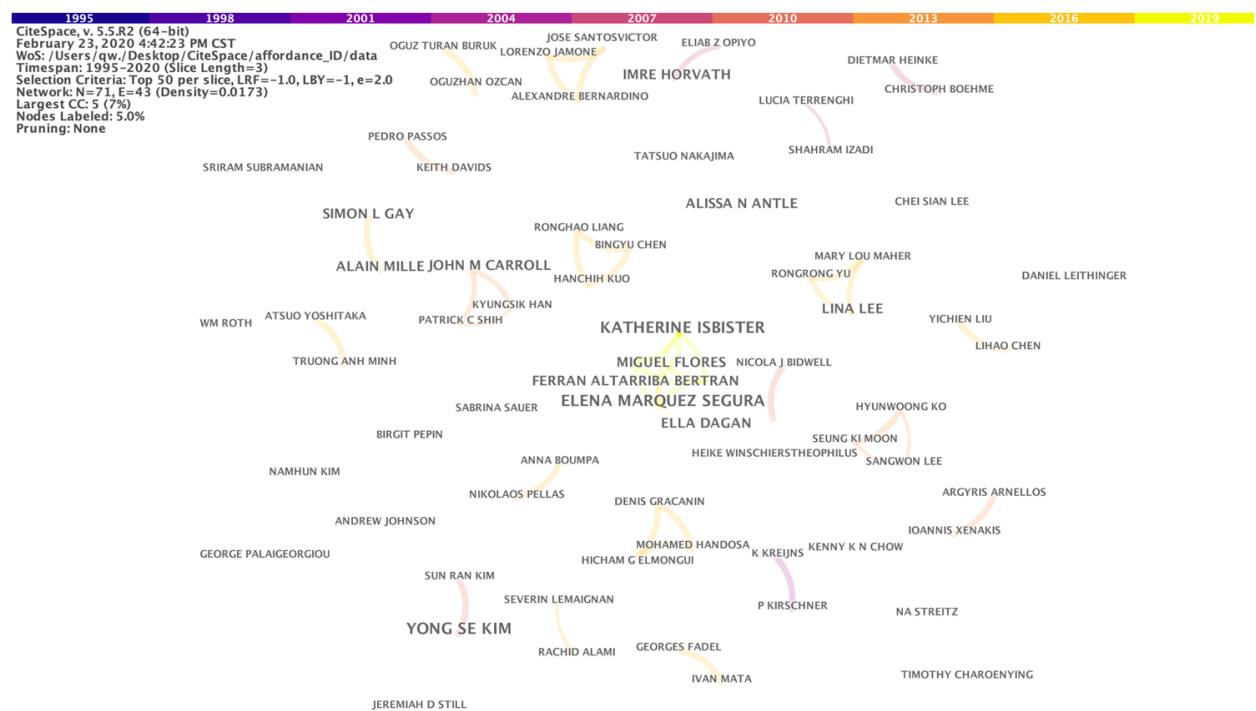

Figure 4. Authors cooperation network.

\section{$4 \quad$ Hot research topics and research fronts on affordances in the field of interaction design}

\subsection{Hot research topics}

Keywords are always representative and concise descriptions of research article content. The hot research topics can be identified through the keyword cooccurrence network generated by CiteSpace[10].

As shown in figure 5, A keyword co-occurrence network pruned by Minimum Spanning Tree (MST) contains 639 nodes and 794 links. The top 15 keywords with high counts and The top 15 keywords with high betweenness centrality were given in table 1. Considering the accuracy of analysis results and relevance of research trend, the keywords "affordance", "design", "interaction design", "human-computer interaction" were removed during analysis. The keywords with high betweenness centrality and counts connected different research topics and revealed the hot topics in the research field. Hot research topics on affordance research in the field of interaction design mainly focus on "perception (count = 41 , centrality $=0.17)$ ", "object $($ count $=10$, centrality $=$ 0.23 )", "system (count $=31$, centrality $=0.22$ )", "usability (count $=9$, centrality $=0.20)$ ", "virtual reality $($ count $=23$, centrality $=0.11)$ ", "information $($ count $=27$, centrality $=0.12)$ ", "student $($ count $=20$, centrality $=$ 0.16)"'.

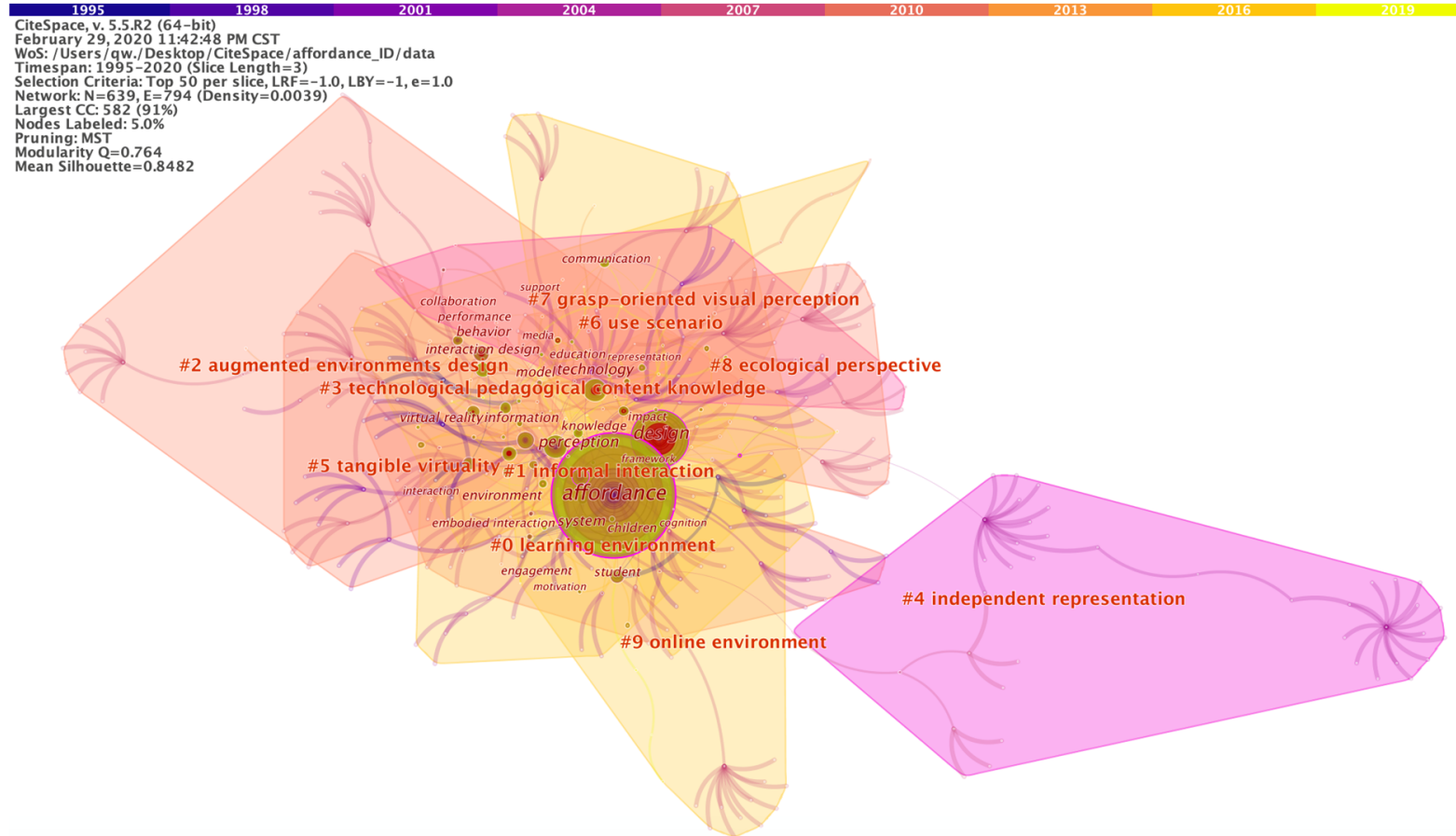

Figure 5. Keyword co-occurrence network. 
Table 1 . Top 15 keywords with high counts and top 15 keywords with high betweenness centrality.

\begin{tabular}{lcccc}
\hline & \multicolumn{2}{c}{ Top 15 keywords with high counts } & \multicolumn{2}{c}{ Top 15 keywords with high betweenness } \\
centrality
\end{tabular}

Cluster analysis can help researchers more efficiently to grasp the research content and topic structure of the research field. The consistency of each cluster was measured by the silhouette (S) value, which ranges from -1 to 1 . In general, if the silhouette values of homogeneous clusters are more than 0.5 , the cluster is generally considered to be reasonable. If the silhouette values are more than 0.7 , the cluster is efficient and convincing. Meanwhile the structure is remarkable with the modularity $(\mathrm{Q})$ value over 0.3 . Figure 5 shows the clusters of the keyword co-occurrence network have high modularity $(\mathrm{Q}=0.764)$ and mean silhouette $(\mathrm{S}=0.8482)$, demonstrating the results with high reliability and credibility. On account of these cluster topics obtained, that relevant literature of these nodes were sorted out with the search function make us summarize the following four research topics:

- Theoretical study including definition, concept and framework on affordances in the field of interaction design, clustered by keywords "model", "system", "framework", "context", "technology", "space", "knowledge", "impact", "tool", "specification", "usability".

- Perception-level study on affordances in the field of interaction design, clustered by keywords "perception", "information", "representation", "perspective", "tangible user interface", "attention", "information visualization", “computer", "cognition", "visual perception".
- Behaviour-level study on affordances in the field of interaction design, clustered by "behavior", "communication", "collaboration", "embodied interaction", "engagement", "children", "instructional design", "motivation".

- Experience-level study on affordances in the field of interaction design, clustered by "virtual reality", "emotion", "augmented reality", "user experience", "innovation", "participation", "immersion".

\subsection{Research fronts}

Timezone view of keyword co-occurrence network mapped by CiteSpace can effectively reveal the dynamic changes of the hot research topics by taking time factor into consideration. As shown in figure 6, the study of affordance research in the field of interaction design can be divided into four phases, reflecting the development path: theoretical study $\rightarrow$ perception $\rightarrow$ behavior $\rightarrow$ experience. The first phase from 1995 to 2003, research topic is to clarify the concept of affordance in interaction design. The second phase from 2004 to 2007, keywords naturally varied from "model", "system", "environment" to "perception", "tangible user interface". The third phase from 2008 to 2013, research focus on the behaviour level, including keywords "behaviour", "collaboration", "play". The fourth phase from 2014 to nowadays, focus on the user experience, user scenarios have become more broader, including "augmented reality", "social media". 


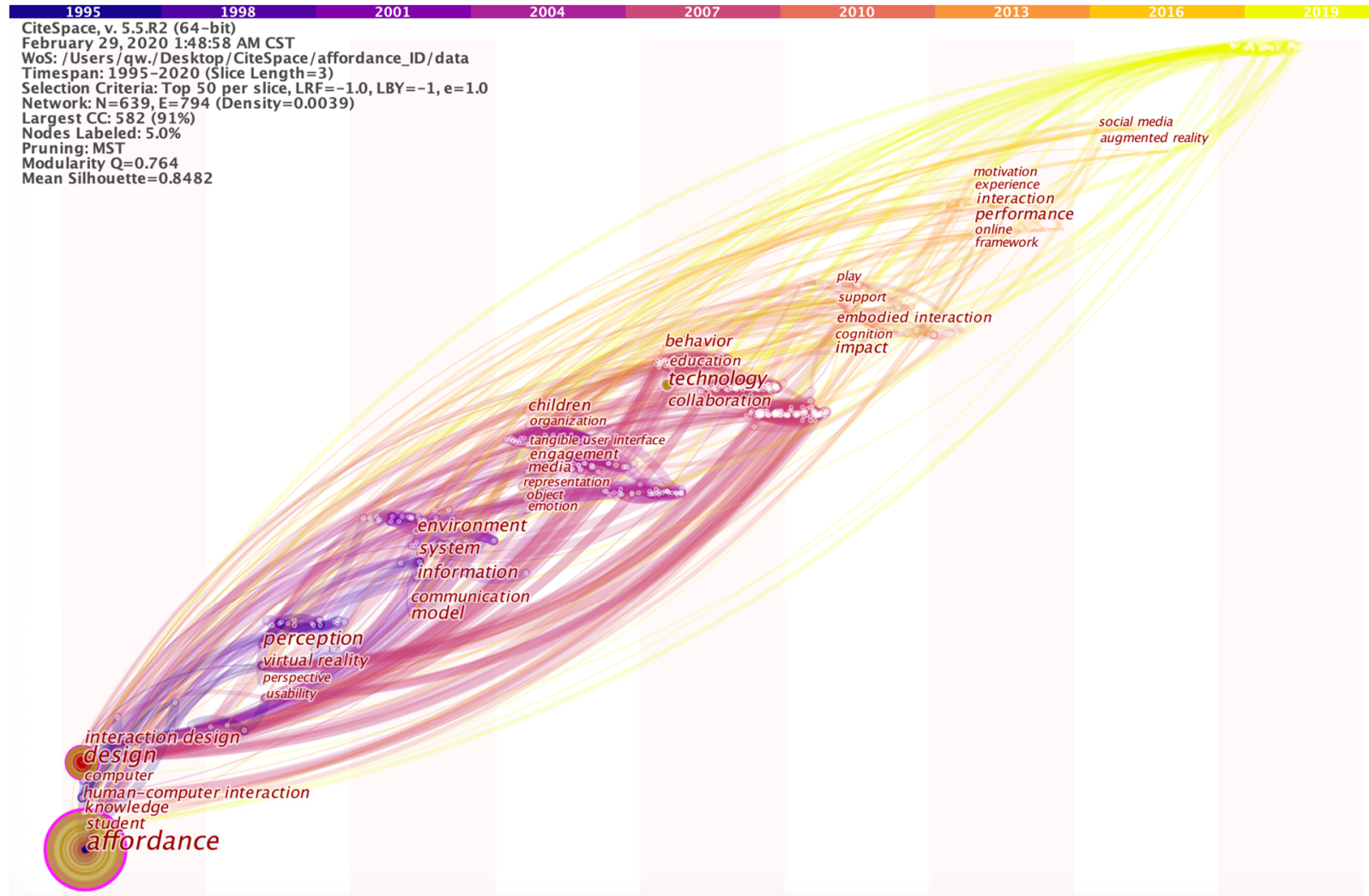

Figure 6. The timezone view of keyword co-occurrence network, 1995-2020.

\section{The intellectual structure of affordance research in the field of interaction design}

Intellectual structure can be mined by tracking the trajectories of references. Figure 7 shows references cocitation network visualized by CiteSpace, containing 405 nodes and 1598 links. The most cited references and records with high centrality are vital data laying a solid foundation for intellectual structure, as shown in table 2.

By comprehensively analyzing the frequency and betweenness centrality of network and cited references, it's obvious to find James Gibson and Donald Norman play important roles in the affordance research in the field of interaction design due to the references from James Gibson and Donald Norman accounting for $40 \%$ of total 20 references with high counts and high centrality. In addition, Brown with the highest betweenness centrality argues that a designer should engage more closely with the social contexts of use and responding more directly to the users in Borderline Issues: Social and Material Aspects of Design[11]. Gaver in his paper Technology affordances firstly provides a discussion of a range of issued need to be clarified about affordance used in HCI, and then, he identifies four possible combinations of the presence or absence of affordances[12]. In Gibson's affordances, Greeno considers Affordances are preconditions for activity. They are properties of whatever the actor interacts with an object in such a way that an activity can be supported [13]. Hartson puts forward four kinds of affordances including cognitive, physical, sensory and functional in his paper Types of affordances and Norman's model of action[14]. These high cited references have make significant contributions to build up the intellectual structure of affordance research in the field of interaction design. 


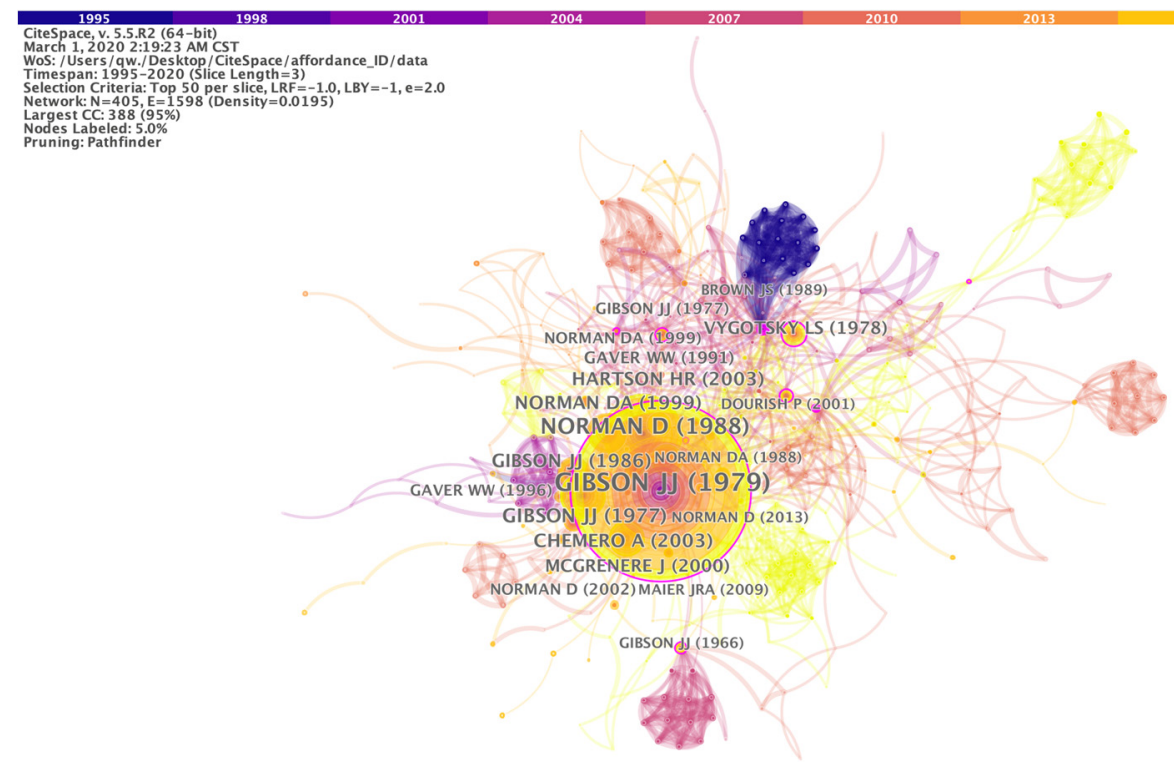

Figure 7. References co-citation network.

Table 2. Top 10 cited references by co-citation counts and top 10 cited references with high betweenness centrality

\begin{tabular}{|c|c|c|c|c|}
\hline \multirow[b]{2}{*}{ Rank } & \multicolumn{2}{|l|}{$\begin{array}{l}\text { Top } 10 \text { cited references by } \\
\text { co-citation counts }\end{array}$} & \multicolumn{2}{|c|}{$\begin{array}{l}\text { Top } 10 \text { cited references with high betweenness } \\
\text { centrality }\end{array}$} \\
\hline & References & $\begin{array}{c}\text { Citation } \\
\text { counts }\end{array}$ & References & $\begin{array}{l}\text { Betweenness } \\
\text { centrality }\end{array}$ \\
\hline 1 & $\begin{array}{l}\text { GIBSON JJ, 1979, ECOLOGICAL } \\
\text { APPROACH, V0, P0 }\end{array}$ & 127 & $\begin{array}{c}\text { BROWN JS, 1989, ED RES, V18, } \\
\text { P32 } \\
\text { HOLLAN J, 2000, ACM }\end{array}$ & 0.44 \\
\hline 2 & $\begin{array}{l}\text { NORMAN D, 1988, PSYCHOL } \\
\text { EVERYDAY THI, V0, P0 }\end{array}$ & 61 & $\begin{array}{l}\text { TRANSACTIONS ON } \\
\text { COMPUTER-HUMAN } \\
\text { INTERACTION, V7, P174 }\end{array}$ & 0.26 \\
\hline 3 & $\begin{array}{l}\text { GIBSON JJ, 1977, PERCEIVING } \\
\text { ACTING KN, V0, P67 }\end{array}$ & 39 & $\begin{array}{l}\text { GIBSON JJ, 1979, ECOLOGICAL } \\
\text { APPROACH, V0, P0 }\end{array}$ & 0.19 \\
\hline 4 & $\begin{array}{l}\text { NORMAN DA, 1999, } \\
\text { INTERACTIONS, V6, P38 }\end{array}$ & 33 & $\begin{array}{l}\text { VYGOTSKY LS, 1978, MIND } \\
\text { SOC DEV HIGHER, V0, P0 } \\
\text { SEGURA EM, 2016, 34TH }\end{array}$ & 0.16 \\
\hline 5 & $\begin{array}{l}\text { GIBSON JJ, 1986, ECOLOGICAL } \\
\text { APPROACH, V0, P0 }\end{array}$ & 33 & $\begin{array}{c}\text { ANNUAL CHI CONFERENCE } \\
\text { ON HUMAN FACTORS IN } \\
\text { COMPUTING SYSTEMS, V0, } \\
\text { P6014 }\end{array}$ & 0.13 \\
\hline 6 & $\begin{array}{l}\text { HARTSON HR, 2003, BEHAV } \\
\text { INFORM TECHNOL, V22, P315, }\end{array}$ & 29 & $\begin{array}{l}\text { GIBSON JJ, 1977, PERCEIVING } \\
\text { ACTING KN, V0, P0 }\end{array}$ & 0.12 \\
\hline 7 & $\begin{array}{c}\text { CHEMERO A, 2003, ECOL } \\
\text { PSYCHOL, V15, P181, DOI } \\
10.1207 / \mathrm{S} 15326969 \mathrm{ECO} 1502 \_5\end{array}$ & 29 & $\begin{array}{c}\text { GREENO JG, 1994, PSYCHOL } \\
\text { REV, V101, P336 }\end{array}$ & 0.12 \\
\hline 8 & $\begin{array}{l}\text { VYGOTSKY LS, 1978, MIND } \\
\text { SOC DEV HIGHER, V0, P0 }\end{array}$ & 24 & $\begin{array}{l}\text { GIBSON JJ, 1966, SENSES } \\
\text { CONSIDERED PE, V0, P0 }\end{array}$ & 0.11 \\
\hline 9 & $\begin{array}{l}\text { MCGRENERE J, 2000, PROC } \\
\text { GRAPH INTERF, V0, P179 }\end{array}$ & 23 & $\begin{array}{l}\text { DOURISH P, 2001, ACTION IS } \\
\text { FDN EMBODI, V0, P0 }\end{array}$ & 0.11 \\
\hline 10 & $\begin{array}{c}\text { GAVER WW, 1991, HUMAN } \\
\text { FACTORS IN COMPUTING } \\
\text { SYSTEMS. REACHING } \\
\text { THROUGH TECHNOLOGY. CHI } \\
\text { 91. CONFERENCE } \\
\text { PROCEEDINGS, V0, P79 }\end{array}$ & 20 & $\begin{array}{l}\text { NORMAN D, 1990, DESIGN } \\
\text { EVERYDAY THIN, V0, P0 }\end{array}$ & 0.11 \\
\hline
\end{tabular}




\section{Conclusions}

This study conducted a scientometric analysis of affordances research in the field of interaction design to visualize the research status quo, track the emerging trends and understand the intellectual structure through co-author analysis, co-word analysis, co-citation analysis and cluster analysis.

Firstly, that annual distribution of publications increases rapidly recent year indicates this study has gotten a lot of attention and will continue to grow. By coauthor analysis, it has formed a cooperative network among United States, United Kingdom, Spain, Denmark, Netherlands and France, Australia. In particular, the USA plays a significant role and is a pioneer in the field. The main research institutions are universities but the research groups are scattered. There is no leading institution or author with high output or high influence. On the whole there is a lack of cooperation among institutions and researchers.

Secondly, the study has formed 4 hot research topics with co-word analysis and cluster analysis: Theoretical study, Perception-level study, Behaviour-level study and Experience-level study. Taking the time factor into consideration, experience-level study is the research front and topic.

Thirdly, references co-citation analysis was performed to find the core references, Gibson and Norman play important roles in the research field. In general, affordance research in the field of interaction design has produced a number of classic literature.

\section{Acknowledgments}

Fund Project: This work was supported by the "Jiangxi Province 2019 Graduate Innovation Fund Project" of Education Department of Jiangxi Province of China (Project Approval Number: YC2019-S231).

\section{References}

1. Gibson, J. J. (1977) The Theory of Affordances. In: Shaw, R., Bransford, J. (Eds.), Perceiving, acting and Knowing. Hillsdale, NJ: Lawrence Erlbaum Associates, pp. 67-82.

2. Norman, D. A. (1988) The Psychology of Everyday Things. Basic Books, New York.

3. Sharp, H., Rogers, Y., Preece, J. (2007) Interaction Design. Beyond Human-Computer Interaction. John Wiley \& Sons, Inc., New York.

4. Hartson, R., Pyla, P. (2012) The UX Book: Process and Guidelines for Ensuring a Quality User Experience. Morgan Kaufmann Publishers Inc., New York.

5. Kaptelinin, V. (2015) Affordances and Design. The Interaction Design Foundation.
6. Ma, C. M. (2016) The Interaction Design Research: A Concept of Affordance Perspective. Doctoral dissertation, Hunan university, Hunan Province.

7. Jesson, J. K., Matheson, L., Lacey, F. M. (2011) Doing your literature review: traditional and system techniques. SAGE Publications, London.

8. Song, J. B., Li, Y., Feng, Z., Wang, H. (2019) Cluster analysis of the intellectual structure of $\mathrm{ppp}$ research. Journal of Management in Engineering, 35(1): 04018053.1-04018053.15.

9. Chen, C. M., Hu, Z. G., Liu, S. B., Tseng, H. (2012) Emerging trends in regenerative medicine: a scientometric analysis in citespace. Expert Opinion on Biological Therapy, 12(5): 593-608.

10. Zhong, B. T., Wu, H. T., L, H., Sepasgozard, S., L, H. B., H, L. (2019) A scientometric analysis and critical review of construction related ontology $\mathrm{T}$ research. Automation in Construction, 101: 17-31.

11. Brown, J. S., Duguid, Paul. (1994) Borderline Issues: Social and Material Aspects of Design. Human-Computer Interaction, 9 (1): 3-36.

12. Gaver, W. W. (1991) Technology Affordances. In: Proceedings of the ACM CHI 91 Human Factors in Computing Systems Conference. New Orleans, Louisiana. pp. 79-84.

13. Greeno, J. G. (1994) Gibson's affordances. Psychological Review, 101(2): 336-342.

14. Hartson, H. R. (2003) Cognitive, physical, sensory and functional affordances in interaction design. Behaviour \& Information Technology, 22(5): 315338. 